http://dx.doi.org/10.5007/2175-7968.2013v2n32p165

\title{
FRASEOLOGIAS NO ENSINO DE TRADUÇÃO
}

\author{
Luciane Leipnitz \\ Universidade Federal da Paraíba \\ luciane.leipnitz@gmail.com
}

\begin{abstract}
Resumo: No ensino de Tradução percebi a existência de fraseologias verbais formadas por compostos nominais e formas verbais coocorrentes, por exemplo: Herzinfarkt erleiden [sofrer infarto cardíaco]. Utilizei corpora de textos jornalísticos para o reconhecimento dessas fraseologias e busquei chamar a atenção de aprendizes de língua alemã e tradução para o funcionamento sintagmático das línguas. $\mathrm{O}$ estudo pretendeu auxiliar no ensino de tradução, apontando a necessidade de uma tradução em blocos sintagmáticos para um produto final de qualidade na língua de chegada - o português brasileiro. Há em geral, nas aulas de tradução, falta de entrosamento com o objeto texto em língua estrangeira. A partir de compostos nominais da área médica, levantei os verbos coocorrentes no Banco de Dados de Coocorrência do Projeto Cosmas da Universidade de Mannheim. A extração de combinatórias por meio de corpora e a apresentação de equivalentes textuais em ambas as línguas (alemão e português) apontaram a complexidade do processo tradutório e a necessidade de reconhecimento do entorno textual dos textos de partida e de chegada para a produção tradutória. Esse "reconhecimento" é fundamental para acionar mecanismos de associação e revelar o modo de dizer particular de cada uma das línguas envolvidas no processo tradutório. As fraseologias correspondem, em certa medida, a expressões idiomáticas, que precisam ser traduzidas em blocos para a produção de um texto de qualidade na língua de chegada. Trata-se de uma pesquisa lexicográfica que objetiva qualificar o ensino de tradução por meio do reconhecimento de fraseologias tanto na língua de partida quanto na língua de chegada.
\end{abstract}

Palavras-chave: Língua Alemã. Compostos Nominais. Fraseologias. 


\title{
TEACHING TRANSLATION THROUGH PHRASEOLOGY
}

\begin{abstract}
In the teaching of translation realized that there are compounds formed by verbal phraseology and co-occurring verbs, eg. Herzinfarkt erleiden [suffering cardiac infarction]. I used corpora of newspaper articles for the recognition of such phraseology and tried to draw the attention of learners of German and translated into the languages syntagmatic operation. The study intended to assist in teaching translation, pointing to the need for a translation syntagmatic blocks for a quality final product in the target language - Brazilian Portuguese. There are generally in the classes of translation, lack of rapport with the object text in a foreign language. From the medical noun compounds, raised co-occurring verbs in Database Project Cosmas from the University of Mannheim. The extraction of combinatorial through corpora and presentation of text equivalents in both languages (German and Portuguese) pointed out the complexity of the translation process and the need for recognition of the surrounding text of the texts of departure and arrival for producing translational. This "recognition" is fundamental to trigger mechanisms of association and reveal the particular way of saying each of the languages involved in the translation process. The phraseology correspond to a certain extent, the idiomatic expressions that must be translated into blocks to produce a quality text in the target language. This is a research that aims to qualify lexicographic teaching translation through recognition of phraseology in both the source language and in the target language.
\end{abstract}

Keywords: German. Noun Compounds. Phraseologies.

\section{Introdução}

A partir de minhas observações em sala de aula em disciplinas de língua e tradução da língua alemã, busquei identificar os pontos de maior dificuldade para o aprendiz em suas primeiras práticas tradutórias. Os compostos nominais já faziam parte de minhas observações enquanto revisora de textos traduzidos da área médica. Busquei observá-los então no processo tradutório de aprendizes e verificar igualmente de que forma foram abordados no ensino de língua alemã. A partir deles, busquei identificar se compunham fraseologias com verbos coocorrentes. 
A partir de um levantamento de dados em corpora de textos jornalísticos em língua alemã, busquei reconhecer e categorizar fraseologias terminológicas, formadas por compostos nominais de textos médicos em língua alemã e as suas respectivas formas verbais coocorrentes (LEIPNITZ, 2010). Objetivei chamar a atenção de aprendizes de língua e tradução da língua alemã para o funcionamento sintagmático das línguas, buscando auxiliar no ensino de tradução para estudantes brasileiros, ressaltando a necessidade de realização de uma tradução em blocos sintagmáticos para um produto final de qualidade na língua de chegada, no caso, o português brasileiro.

A observação da produção textual em língua portuguesa a partir de traduções de textos em língua alemã mostrou que os estudantes estavam ainda "presos" a estruturas e noções gramaticais dos livros didáticos e que, consequentemente, realizavam ainda uma tradução palavra por palavra, cujo resultado era um texto sem fluência na língua portuguesa. Os compostos nominais e seus entornos textuais mostram-se como estruturas de dificuldade constante para os estudantes. Paralelamente, percebi que essas estruturas não recebiam a devida atenção no ensino de língua estrangeira.

Para evidenciar a existência dessas combinatórias textuais, realizei pesquisa em corpora, buscando suas ocorrências textuais, de forma a mostrar ao aprendiz de tradução que esses segmentos textuais apresentam certo grau de fixidez entre os elementos tanto na língua de partida quanto em sua tradução para a língua de chegada. Da compreensão dessa coocorrência entre os itens lexicais depende uma tradução de qualidade, que observe o modo de dizer de cada uma das línguas envolvidas no processo tradutório, culminando na produção de um texto fluente na língua de chegada.

\section{Identificando fraseologias a partir de termos médicos}

Tomei textos jornalísticos em língua alemã para o levantamento das fraseologias formadas por compostos nominais e verbos coocorrentes. Os compostos nominais foram retirados de textos médicos. 
As composições nominais em língua alemã (Komposita) são constituídas basicamente de uma base e um determinante, sendo a base a parte final do composto e o determinante a parte inicial. Relacionam-se à base os traços gramaticais como gênero, número, caso e flexão. O determinante tem, em geral, a função de atributo, e pode ser constituído de um ou mais substantivos, adjetivos ou verbos, mais raramente por pronomes, interjeições ou numerais. O determinante não é flexionado. A tradução de um composto nominal (substantivo + substantivo) para o português corresponde, em geral, a forma "nome + preposição + nome", mas pode também apresentar a forma "nome + adjetivo". Assim, por exemplo, tem-se das Herz $($ subst.neutro $=$ o coração $)+$ der Infarkt (subst.masc. $=$ o infarto $)$, na composição, der Herzinfarkt (o infarto cardíaco ${ }^{1}$ ).

Em minha pesquisa, considerei apenas as formações com a presença explícita de elementos verbais (PICHT, 1990a), embora na língua alemã uma fraseologia terminológica possa ser expressa por uma palavra gráfica, sem que o elemento verbal esteja à direita ou à esquerda (ZILIO, 2009). Assim, a partir de uma fraseologia sem a presença da forma verbal Herzinfarkterkrankung [acometimento por infarto cardíaco], a pesquisa se ocupou da composição nominal e a forma verbal coocorrente, considerando também, quando necessário, a partir do verbo a preposição por ele exigida na formação, por exemplo, an Herzinfarkt erkranken [ser acometido por infarto cardíaco].

\section{Dificuldade de identificação e tradução de fraseologias}

Sabe-se que há, em todas as línguas, estruturas pré-fabricadas, utilizadas pelos falantes em suas produções linguísticas, que não são determinados apenas por regras livres do sistema. São combinações estáveis de palavras, de uso geral na língua e de extrema importância para a aquisição e o processamento tanto da língua de partida quanto da língua de chegada. A existência dessas formações pode ser confirmada pelo estudo em corpora, o qual revela o papel 
central dessas formações na produção linguística (CORPAS PASTOR, 1996, p.14).

No aprendizado de língua estrangeira, tem-se expressões cujo significado é diferente da soma das partes. E a tentativa de produzir ou compreender um texto muitas vezes é frustrada, pois a simples consulta a um dicionário bilíngue não contempla a solução de tais expressões.

A experiência docente mostrou-me a necessidade de destacar, para o aprendiz de tradução, elementos do funcionamento sintagmático das línguas. Verifiquei que os aprendizes de tradução não observavam a língua como um sistema de interrelações, realizando traduções de elementos em separado e segmentando associações que não podiam ser separadas, o que conduzia à fragmentação do texto traduzido.

A tradução compreende, inicialmente, um processo de leitura e de compreensão do texto de partida, que não depende apenas de conhecimentos na língua estrangeira e exige uma série de competências por parte do tradutor (receptor do texto de partida e produtor do texto de chegada). A competência tradutória pode ser desenvolvida por meio da ativação de habilidades tradutórias. Na pesquisa empreendida, destaco a visualização da vinculação de elementos que se co-selecionam como elemento-chave para o desenvolvimento da competência tradutória do aprendiz. Trata-se de perceber a língua em seu uso real.

\section{Referencial teórico}

A existência de fraseologias não causa estranheza a nenhum observador da língua. Entretanto, essas formações parecem algumas vezes mais fixas e idiomáticas, em outras nem tão fixas nem tão idiomáticas. Por isso, definir o objeto da pesquisa não foi algo fácil. O que esteve sempre claro foi que não são formações totalmente livres, pois entre seus elementos formadores há uma frequência de coocorrência. 
A pesquisa observa fraseologias a partir de compostos nominais de textos médicos, em contexto de uso, envolvendo estudos de Terminologia de perspectiva textual e comunicativa. Dessa forma, busca evidenciar que a especificidade das linguagens especializadas não se limita às terminologias, mas considera também o uso de determinadas categorias gramaticais, construções sintáticas e estruturas textuais (KRIEGER e FINATTO, 2004, p.35-58). Observam-se termos em textos, ou seja, unidades léxicas que se atualizam como termos ou palavras, de acordo com fatores textuais de ordem superior (CIAPUSCIO, 2003, p.46). Parte-se de textos para o estudo de construções sintagmáticas, buscando evidenciar convencionalidades textuais (ZILIO, 2009, p.31), formadas a partir de elementos coocorrentes.

Para observar fraseologias em língua alemã, considerei diversos estudos sobre o tema, abordados sob a perspectiva de diferentes autores.

Gottsched, já em 1762, mencionara a problemática desses segmentos para a tradução, referindo-os como os "modos de dizer de nossa língua, que não são possíveis de traduzir palavra por palavra para uma outra língua" (p.538, apud FLEISCHER, 1982, p.9).

Thun (1978, p.33-70) faz referência a "unidades fraseológicas" e considera o caráter de "fixidez" desses grupos de palavras, que pode ser observado pela repetição no discurso.

Fleischer (1982, p.7) considera que esses grupos de palavras podem ser estáveis e que compõem o vocabulário de uma língua, assim como a formação de novas palavras (neologismos), os empréstimos e as mudanças de significado de unidades monoléxicas.

Irsula Peña $(1992$, p. 1) refere-se à complexidade de tais segmentos no ensino de língua estrangeira, por serem partes "constitutivas da produção textual, sem as quais não se produziria texto em língua estrangeira". Refere-se à importância da consideração da idiomaticidade e da necessidade de pesquisa dessas unidades, de uso frequente na comunicação, as quais devem ser bem compreendidas e corretamente transpostas para a língua-alvo (IRSULA PEÑA, 1992, p.15). 
Burger (2007, p. 14-15) refere-se às propriedades dessas unidades fraseológicas: polilexicalidade, estabilidade e idiomaticidade. A estabilidade compreende o reconhecimento e o uso dessa unidade polilexical pelos membros de uma comunidade linguística do mesmo modo como reconheceriam e usariam unidades monolexicais. A idiomaticidade corresponde ao fato de o significado do todo ser diferente da soma dos significados das partes.

Visto que não se pesquisam frases genéricas dedutíveis, mas textos empíricos, de acordo com um contexto situacional. Essas "colocações" são fenômenos do contexto sintagmático, no qual duas ou mais palavras estruturais se colocam juntas (LEHR, 1996, p.22), e correspondem ao uso efetivo da língua, ou seja, estão ligadas a um cotexto e a um contexto situacional.

Irsula Peña $(1992$, p.30) refere uma microestrutura, formada pela base e por um colocado atual, e uma macroestrutura, que reflete tanto as relações da base com outros potenciais colocados como também as relações dos colocados entre si. A base corresponderia ao composto nominal nesta pesquisa. A partir dessa base, tem-se verbos coocorrentes, que são os colocados, os quais determinam o significado mais aproximado da formação. Tem-se, por exemplo, a base Herzinfarkt (infarto cardíaco), que seleciona os verbos erleiden ou leiden (sofrer). Ao selecionar o segundo verbo, não prefixado ("er-" corresponde ao prefixo $\left.{ }^{2}\right)$, este seleciona uma preposição por ele exigida unter ou an (que corresponderiam, em português, à preposição "de"), outro colocado. Assim, os segmentos em língua alemã "einen Herzinfarkt erleiden" e "unter/an einen Herzinfarkt leiden", na tradução para o português, assumem a forma única "sofrer um infarto cardíaco", tendo em vista a regência do verbo "sofrer".

As fraseologias compreendem estruturas com relações horizontais e verticais. Nos níveis horizontais, estão os colocados, que indicam cenas das quais a base eleita toma parte. Os níveis verticais representam as próprias cenas. Um colocado ou uma série de potenciais colocados se coloca à disposição, de acordo com a situação 
e as restrições próprias da língua, para a participação no referido acontecimento (IRSULA PEÑA, 1992, p.30-31).

Por exemplo, sinônimos dos verbos coocorrentes com os compostos nominais da área médica estariam em relação horizontal com a base (o composto nominal), mas, em relação aos demais verbos, apresentariam uma relação vertical no eixo paradigmático. Assim, por exemplo, há relações verticais entre os sinônimos do verbo sich erholen [restabelecer-se]: genesen, gesunden, sich regenerieren. $\mathrm{O}$ verbo genesen apresenta relações horizontais com as bases Lungenentzündung [pneumonia], Herzoperation [operação cardíaca] e Herzattacke [ataque cardíaco], tendo em vista as mesmas bases terem coocorrido com o verbo sich erholen e ambos os sinônimos expressarem um mesmo acontecimento. Entretanto, alguns sinônimos não confirmam relações horizontais com os mesmos compostos nominais e não expressam, com os seus coocorrentes, as mesmas relações de sentido, ou seja, acontecimentos semelhantes. É o caso, por exemplo, do verbo erleben, apresentado como sinônimo do verbo leiden [sofrer]. A partir de leiden, foram identificados vários compostos nominais da área médica: Schlafstörung [perturbação do sono], Kopfschmerz [dor de cabeça], Bluthochdruck [pressão alta], Atemwegserkrankung [acometimento das vias respiratórias], Haarausfall [queda de cabelo], dentre outros. Como coocorrente de erleben, registrou-se Zahnbehandlung [tratamento dentário]. Entretanto, os sinônimos não apresentam o mesmo sentido, os acontecimentos são distintos, as cenas são diferentes. Portanto, esses sinônimos não podem ser substituídos um pelo outro sem alterar o acontecimento, pois correspondem a níveis diferentes.

Diferenças de código e em seus modos de realização são causas de erros frequentes dos falantes não-nativos, que transferem as regras da língua materna para a língua estrangeira (IRSULA PEÑA, 1992, p.46). Colocações usuais em uma língua são reproduzidas por seus usuários, trata-se da "norma social da língua". Essas restrições de uso são diferentes de língua para língua e comumente determinadas pelo uso histórico. A arbitrariedade desse fenômeno pode ser atestada por todo o falante não-nativo. $\mathrm{O}$ aprendiz de lín- 
gua e tradução deve aprender sobre as combinatórias como unidades compactas a partir do reconhecimento de tais restrições.

O composto nominal (substantivo), em minha pesquisa, foi considerado a base para potenciais colocações. O substantivo corresponde a uma classe com potencial para a formação de sintagmas. A escolha de um verbo para representar um acontecimento dependente de necessidades imanentes da língua, sendo condicionada sintática e semanticamente. O que comprovou empiricamente esse condicionamento foi a impossibilidade de substituição, na combinatória, do verbo por um sinônimo ou a não permissão de substituição do composto por um equivalente greco-latino ${ }^{3}$.

Assim, os coocorrentes da pesquisa comprovaram-se combinatórias de palavras não-fixas, mas não totalmente livres, que correspondem a fraseologias terminológicas, por serem formados a partir de termos médicos e, portanto, características desse âmbito textual.

Este estudo comparativo entre língua alemã e língua portuguesa objetivou chamar a atenção sobre a complexidade do processo tradutório e a necessidade de consideração do cotexto e do contexto para uma qualificada "equivalência" de sentido no texto de chegada. Trata-se da transferência da função comunicativa dos segmentos textuais da língua alemã para a língua portuguesa, considerados em um contexto social. Tomaram-se as competências necessárias para a produção de um texto traduzido de qualidade, considerando a possibilidade de incrementar a competência tradutória ao longo da formação do profissional tradutor. Trata-se do desenvolvimento da competência em tradução de um saber fazer para uma reflexão sobre o que envolve o fazer tradutório, que pode ser estimulada por meio de ferramentas de auxílio ao aprendiz (ALBIR, 2007).

\section{Corpus e coleta de dados}

Efetuei o levantamento dos coocorrentes com os compostos nominais no Banco de Dados de Coocorrências ${ }^{4}$ do Projeto Cosmas 
(Corpus Search, Management and Analysis System) do Instituto para Língua Alemã (IDS) da Universidade de Mannheim 5 .

Utilizei como palavras de busca Komposita retirados de textos médicos e apenas compostos na forma substantivo-substantivo. A partir dos compostos, busquei as coocorrências verbais e, a partir destas, novos coocorrentes nominais. Através da categorização das formações, identifiquei o Kompositum na função de sujeito ou de objeto direto (acusativo) nas combinatórias, correspondendo a um núcleo terminológico ligado a um núcleo verbal.

Tomei então os verbos coocorrentes com os Komposita como palavras de busca para levantamento dos compostos de maior frequência. Ao levantar novos Komposita a partir de verbos coocorrentes, busquei evidenciar um espectro maior de opções combinatórias, tendo utilizado o critério da frequência como forma de controle dessas coocorrências e o exemplo em cotexto para evidenciar, empiricamente, os resultados.

Assim, a partir der Herzinfarkt [infarto cardíaco], verifiquei a coocorrência do verbo leiden [sofrer] e, a partir deste verbo, novos compostos nominais, como Kopfschmerz [dor de cabeça], Bluthochdruck [pressão alta], Atemwegserkrankung [acometimento das vias respiratórias], Gedächtnissschwund [amnésia], Magersucht [anorexia], Haarausfall [queda de cabelos], Stoffwechselkrankheit [doença metabólica]. Foram então selecionados os coocorrentes de maior frequência que atendiam aos critérios de busca da pesquisa (compostos nominais da área médica).

A confirmação das coocorrências se deu por meio de exemplos em corpus, que buscaram evidenciar a vinculação sintática dos itens coocorrentes e, consequentemente, uma interdependência semântica. Essa interdependência implica a necessidade de compreensão do todo dos segmentos na língua alemã e a busca pela unidade de sentido equivalente na tradução para o português.

$\mathrm{O}$ quadro apresenta a sequência de passos da busca por coocorrentes nominais a partir de formas verbais e os exemplos em cotexto para a confirmação da vinculação entre as unidades: 


\begin{tabular}{|l|l|l|}
\hline $\begin{array}{l}\text { Verbo } \\
\text { coocorrente }\end{array}$ & $\begin{array}{l}\text { Composto } \\
\text { nominal }\end{array}$ & Exemplos em corpora \\
\hline leiden & Kopfschmerzen & $\begin{array}{l}\text { Patienten leiden auch an starken } \\
\text { Kopfschmerzen } \\
\text { [Pacientes também sofrem de for- } \\
\text { tes dores de cabeça.] } \\
\text { Frauen leiden oft unter starken } \\
\text { Kopfschmerzen } \\
\text { [Mulheres com frequência sofrem } \\
\text { de fortes dores de cabeça.] } \\
\text { Jugendlichen, die unter quälen- } \\
\text { den Kopfschmerzen leiden } \\
\text { [Jovens, que sofrem de terríveis } \\
\text { dores de cabeça.] }\end{array}$ \\
\hline
\end{tabular}

Os exemplos em corpora possibilitaram a categorização das unidades, evidenciando a vinculação sintática dos itens coocorrentes e, consequentemente, uma interdependência semântica. Foi para essa interdependência de sentido que busquei chamar a atenção do aprendiz de tradução, mostrando a necessidade de compreensão do todo dos segmentos na língua alemã e a busca pela unidade de sentido equivalente na tradução para o português.

A relevância em corpora está diretamente relacionada à frequência de coocorrência. Palavras que coocorrem com frequência comprovam, assim, formas de uso da língua. Fraseologias com frequência de coocorrência tanto em língua alemã quanto em língua portuguesa foram consideradas relevantes nesta pesquisa. Tomei o grau de repetição dos segmentos no discurso como critério de frequência, tendo observado o modo de dizer em ambas as línguas e nas respectivas linguagens médicas. Foram consideradas coocorrências expressivas, por exemplo, Herzinfarkt erleiden [sofrer 
infarto cardíaco] (12.019 cocoocorrências) ${ }^{6}$, que foram julgadas merecedoras de registro, visto que, de alguma forma, espelham a língua em uso na linguagem médica em língua alemã e no português brasileiro.

\section{Descrição dos dados}

As fraseologias Komposita médicos e formas verbais coocorrentes evidenciam a sintagmatização da língua alemã, apresentando os Komposita com papel nuclear nas formações. Os verbos destacaram-se como os principais elementos orbitais. As associações entre verbos e Komposita são determinadas pelos compostos. Trata-se de segmentos mais ou menos fixos, pois, embora, um mesmo composto possa constituir combinatórias com outras formas verbais, assim como os verbos também se vinculem a diferentes compostos, essas associações não são totalmente livres, há uma espécie de seleção pelo composto nominal do verbo com ele coocorrente.

Para evidenciar essa seleção, utilizei como palavras de busca as formas sinonímicas dos verbos alemães. Formas nominais distintas foram então registradas como coocorrentes. Assim, por exemplo, o verbo leiden [sofrer] mostrou-se coocorrente com diversos compostos nominais oriundos de textos médicos, dentre eles: Schlafstörung [perturbação do sono], Kopfschmerz [dor de cabeça], Bluthochdruck [pressão alta], Atemwegserkrankung [acometimento das vias respiratórias], constituindo combinatórias na seguinte forma: unter Schlafstörung leiden [sofrer de perturbação do sono]. Ao substituir o verbo leiden pelas formas dulden, erdulden, erleben, ertragen, aushalten ou empfinden, apontadas como sinonímicas por dicionários alemães de sinônimos e valência verbal (BULITTA, 1993; SCHUMACHER, 2004), obtive como resultados alguns itens lexicais relacionados à área médica (por exemplo, Schmerz [dor]), mas que não correspondiam a composições nominais. Quando houve o registro de compostos nominais, obser- 
vei alteração do sentido do verbo. Por exemplo, na combinatória Zahnbehandlung erleben, tem-se alteração do sentido do verbo se comparado com a forma unter/an...leiden. O sentido de "sofrer" deixa de ser "padecer de, ter sido acometido por", passando a ser "submeter-se a, experimentar, passar por" na combinatória com "tratamento dentário".

\section{Considerações finais}

Ao realizar uma observação de combinatórias em textos jornalísticos em língua alemã, pretendi mostrar que os termos e seus segmentos especializados correspondem à língua em uso e não existem isolados dos textos, mas neles inseridos. Esta pesquisa pretendeu contribuir para o ensino de tradução, apresentando ao aprendiz, através de dados empíricos em corpora, o funcionamento sintagmático das línguas - alemão e português.

A partir da percepção do papel dessas associações, o estudante de tradução deverá compreender que tais formações têm funcionamento distinto nas diferentes línguas e nos diferentes tipos de textos em que ocorrem. Detentor desse conhecimento, terá condições de compreender o texto traduzido como algo que precisa ser coerente com essas associações e com as demais condições da língua e da cultura de chegada. Trata-se da consideração do "como se diz" na língua de chegada que tornará seu texto traduzido um produto de qualidade, sem formas marcadas de uma tradução "palavra por palavra" e "presa" ao texto-fonte.

A compreensão da tradução para além de termos isolados é peça-chave para uma tradução competente. A identificação e a compreensão das estruturas das unidades, inicialmente na língua-fonte, e, num segundo momento, na língua-alvo, contribuem para o desenvolvimento da competência tradutória do estudante aprendiz, no sentido da ampliação do foco tradutório para além do termo como objeto isolado. Trata-se de verificar que o sistema da língua alemã, 
formado de unidades que se condicionam mutuamente, distinguir-se-á do sistema da língua portuguesa pela organização interna dessas unidades. Considerar os fenômenos não mais como uma soma de elementos que devem ser isolados, analisados, dissecados, mas como conjuntos, que se constituem como unidades relativamente autônomas, que manifestam solidariedade interna e têm leis próprias. A língua vista como uma entidade autônoma de dependências internas, como uma estrutura, cujas partes se condicionam reciprocamente, cada uma dependente de "determinadas" outras.

Os dados da pesquisa confirmaram que os compostos nominais estabelecem relações com as formas verbais coocorrentes. As combinatórias Kompositum + forma verbal coocorrente correspondem a sintagmatizações, cujos elementos se condicionam reciprocamente. A substituição dos verbos pelos seus sinônimos demonstrou a existência de relações paradigmáticas. As formas sinonímicas dos verbos coocorrem com compostos nominais distintos, o que aponta o grau de fixidez da combinatória. Há, portanto, uma espécie seleção recíproca entre os itens que formam a combinatória.

Ao considerar que a tradução corresponde a uma capacidade de reflexão sobre o fazer, um conhecimento que se adquire com a prática e com a reflexão sobre a prática, a pesquisa em corpora e os dados empíricos revelados pretendem servir ao desenvolvimento de competências linguísticas em língua materna e em língua estrangeira, por meio da observação do funcionamento real da língua, promovendo, consequentemente, o desenvolvimento da competência tradutória do aprendiz. 


\section{Notas}

1. Saliente-se aqui que é característica da linguagem médica brasileira a adjetivação do determinante, especificador da composição. Assim, tem-se, por exemplo: contração muscular [Muskelkontraktion], tratamento dentário [Zahnbehandlung], operação cardíaca [Herzoperation]. Em minha dissertação de mestrado (LEIPNITZ, 2005), analisei quais eram e como se traduziam para o português os compostos nominais de textos médicos.

2. É característica da língua alemã a existência de verbos prefixados, a partir de formas verbais já existentes. Trata-se, em geral, de uma especificação do sentido do verbo (DUDEN, 1998, p.447). A prefixação pode também alterar a transitividade do verbo (WELKER, 2004, p.117). A prefixação em língua alemã compreende prefixos separáveis e não-separáveis na conjugação. Os prefixos não-separáveis permanecem sempre junto ao radical do verbo (é o caso do prefixo "er-"). A tonicidade no prefixo ou na raiz do verbo o identifica como um verbo separável ou não.

3. Por exemplo, tem-se Bluthochdruck [pressão arterial alta] senken [baixar] ou diagnostizieren [diagnosticar], enquanto com Hypertonie [hipertonia] (correspondente greco-latino da composição Bluthochdruck) tem-se como coocorrentes os verbos vertreiben [expulsar, repelir]) e darstellen [representar].

4. Disponível para acesso no endereço, http://corpora.ids-mannheim.de/ccdb/.

5. Os corpora do Projeto correspondem a uma coletânea de textos em língua alemã, utilizada como base empírica para o desenvolvimento de pesquisas linguísticas, através de vários projetos, dentre os quais, o Cosmas 1 e o Cosmas 2 (disponíveis para consulta em http://www.ids-mannheim.de/kl/projekte/cosmas_I e http://www.ids-mannheim.de/cosmas $2 /$, respectivamente). Para essa escolha, considerei a extensão da coletânea de textos, o fato de se constituir de textos autênticos em língua alemã, em sua maioria publicações de jornais diários e a disponibilidade de acesso online para fins de pesquisa linguística.

6. Resultados apresentados nas buscas no Banco de Dados de Coocorrência (http://corpora.ids-mannheim.de/ccdb/) do Projeto Cosmas da Universidade de Mannheim, que possui um total de 2,2 bilhões de palavras. 


\section{Referências}

ALBIR, Amparo Hurtado. Traducción y Traductología. Introducción a la traductología. Madrid: Cátedra, 2007.

BULITTA, Erich und Hildegard. Das Kruger Lexikon der Synonyme. Frankfurt am Main: Krüger, 1993.

BURGER, Harald. Phraseologie. Eine Einführung am Beispiel des Deutschen. 3.neu bearbeitete Auflage. Berlin: Erich Schmidt Verlag, 2007. Grundlagen der Germanistik.

CIAPUSCIO, Guiomar. Textos especializados y terminologia. Barcelona: IULA, 2003.

CORPAS PASTOR, G. Manual de fraseología española. Madrid: Gredos, 1996. p.14-52.

DUDEN. Die Grammatik der deutschen Gegenwartssprache. 6. neu bearbeitete Auflage. Mannheim, Leipzig, Wien, Zürich: Dudenverlag, 1998. Band 4.

FLEISCHER,Wolfgang. Phraseologie der deutschen Gegenwartssprache. Leipzig: VEB Bibliographisches Institut Leipzig, 1982.

IRSULA PEÑA, Jesus Ismael. Substantiv-Verb-Kollokationen. Ein Beitrag zur Phraseologieforschung im Sprachvergleich Deutsch-Spanisch. Leipzig: Universität Leipzig, 1992. Dissertation (Universität Leipzig), Juli 1992.

KRIEGER, Maria da Graça; FINATTO, Maria José. Introdução à terminologia: teoria e prática. São Paulo: Contexto, 2004.

LEHR, Andrea. Kollokationen und maschinenlesbare Korpora. Ein operationales Analysemodell zum Aufbau lexikalischer Netze. Tübingen: Max Niemeyer Verlag, 1996. 
LEIPNITZ, Luciane. Compostos nominais em língua alemã em medicina em tradução para o português. Porto Alegre: UFRGS, 2005. Dissertação (Mestrado em Letras). Instituto de Letras, Universidade Federal do Rio Grande do Sul, Porto Alegre, 2005.

. Da descrição dos usos da língua ao ensino da tradução: combinatórias textuais em língua alemã e implementação do ambiente VirtuaLern. Porto Alegre: UFRGS, 2010. Tese (Doutorado em Letras). Instituto de Letras, Universidade Federal do Rio Grande do Sul, Porto Alegre, 2010.

PICHT, Heribert. LSP Phraseology from the terminological point of view. Terminology science \& research: Journal of International Institute for Terminology Research, v. 1, n. 1-2, 1990a.

SCHUMACHER, Helmut. VALBU - Valenzwörterbuch deutscher Verben. Tübingen: Narr, 2004.

THUN, Harald. Probleme der Phraseologie. Untersuchungen zur wiedeholten Rede mit Beispielen aus dem Französischen, Italienischen, Spanischen und Rumänischen. Tübingen: Max Niemeyer Verlag, 1978. (Beihefte zur Zeitschrift für Romanische Philologie. Band 168)

WELKER, Herbert Andreas. Gramática Alemã. Brasília: Edunb, 2004.

ZILIO, Leonardo. Colocações especializadas e Komposita: um estudo contrastivo alemão-português na área de Cardiologia. Dissertação (Mestrado em Letras). Instituto de Letras, Universidade Federal do Rio Grande do Sul, Porto Alegre, 2009.

Recebido em 16/12/2012 Aceito em 05/06/2013 